\title{
Dossiê
}

Partidos políticos, eleições e comportamento político-eleitoral no Brasil

\section{Evolução da competição eleitoral municipal no Brasil (1996 a 2012)}

\author{
Vitor de Moraes Peixoto \\ Professor Associado da Universidade Estadual Norte Fluminense \\ Coordenador do Laboratório de Estudo do Estado e da Sociedade Civil \\ Nelson Luis Motta Goulart \\ Mestrando do Programa de Sociologia Política - CCH - UENF
}

\begin{abstract}
Resumo: Por vezes interpretados pelos analistas políticos como locais de fragilidade do sistema partidário em que os "mandões" exercem seus desígnios sem limites, os chamados grotões eleitorais permanecem como fenômeno pouco estudado no Brasil. O objetivo deste paper é produzir uma análise sistemática sobre a competição eleitoral nas eleições municipais brasileiras ocorridas entre 1996 e 2012. A questão analítica que se coloca refere-se aos possíveis fatores sociodemográficos, políticos e econômicos dos municípios que estão associados à maior ou menor competição eleitoral nas eleições para prefeitos e vereadores no Brasil. Demonstra-se, por fim, como a competição pode ser explicada mais por meio das características institucionais do sistema eleitoral, e menos pelas características sociodemográficas dos municípios.
\end{abstract}

Palavras-chave: Democracia; institucionalismo; eleições municipais; competição eleitoral; grotões eleitorais.

Abstract: Sometimes interpreted by political analysts as places of party system instability where the "bossy" ones use their designs without limits, the so-called electoral "grotões" remains an understudied phenomenon in Brazil. The objective of this paper is to analyze, in systematic way, the electoral competition in the Brazilian municipal elections held between 1996 and 2012. The analytical question refers to the possible socio-demographic, political and economic factors of the municipalities that are associated with greater or smaller electoral competition in elections for mayors and councilors in Brazil. It is shown, finally, how competition can be explained more by the institutional characteristics of the electoral system, and less by the socio-demographic characteristics of municipalities.

Keywords: Democracy; institutionalism; municipal elections; electoral competition; electoral "grotões". 


\section{Sistemas políticos municipais brasileiros}

Os municípios brasileiros, principalmente os menores, mais pobres e localizados no Norte e Nordeste, são interpretados como locais de fragilidade do sistema partidário e propícios à reprodução dos desmandos dos "coronéis", tais quais eternizados por Victor Nunes Leal em "Coronelismo, enxada e voto" (1975). O interior brasileiro é tomado pelos analistas políticos como terras férteis para os "mandões" exercerem seus desígnios sem limites. Não obstante a intensa presença destas concepções na imprensa, os chamados "grotões eleitorais" permanecem como fenômeno pouco estudado no Brasil. O objetivo deste paper é produzir uma análise sistemática sobre a evolução da competição eleitoral nas eleições municipais brasileiras de 1996 até 2012, portanto, ao longo das cinco últimas eleições. A questão analítica que se coloca refere-se aos possíveis fatores sociodemográficos, políticos e econômicos dos municípios que estão associados à maior ou menor competição eleitoral nas eleições para prefeitos e vereadores no Brasil e, principalmente, como os partidos vêm se comportando no que concerne à capilaridade eleitoral. Demonstra-se, por fim, como a competição eleitoral, aumentando gradativamente, principalmente nas eleições proporcionais, pode ser explicada mais por meio das características institucionais do sistema eleitoral, e menos pelas características sociodemográficas.

Em um dos mais influentes empreendimentos teóricos da democracia liberal, Poliarquia, de Robert Dahl (1997), apresenta duas dimensões que permitem identificar e classificar os sistemas do mundo real de acordo com os ideais democráticos, quais sejam, contestação pública e participação.' A primeira dimensão diz respeito exatamente ao que se pode traduzir por competição institucionalizada, que requer que os participantes - governos e oposições - tenham incentivos institucionais para aderirem às regras do jogo e respeitarem os resultados eleitorais. Ainda que Dahl não considerasse a competição como um atributo suficiente para o desenvolvimento de um sistema democrático, ela figura em toda sua obra como uma pré-condição para a poliarquia.

Se, por um lado, Dahl estava preocupado com as variáveis político-institucionais que aumentavam a participação e oposição dos sistemas políticos; por outro, estudos

1 Robert Dahl, no livro Um prefácio à teoria democrática, editado pela primeira vez em 1952 (Dahl, 2006), já havia demonstrado preocupações nesse sentido e apresentou o embrião do que viria a ser melhor desenvolvido em 1971 em Poliaquia (Dahl, R., 1997). 
desenvolvidos pela sociologia política se debruçavam sobre as características das estruturas sociais que funcionavam como insumos necessários para o estabelecimento da democracia. Uma das obras mais marcantes dessa corrente foi O homem político (Lipset, 1967), cuja perspectiva era a de que os sistemas políticos refletiriam os avanços alcançados em outras áreas da sociedade, tais como a urbanização, industrialização, escolarização, principalmente, por consequência da emergência de uma classe média robusta. Dito de outro modo, quanto maior o nível de modernização de um determinado país tanto mais propenso estaria a sustentar instituições democráticas. Em resumo, a cadeia de causalidade proposta pode ser expressa na forma que se segue: o crescimento econômico impele a sociedade a uma intensa urbanização e a um crescimento das classes médias. Estas, por sua vez, com maior acesso à educação e maior probabilidade de mobilidade social, tendem a ser mais propícias às modificações incrementais das instituições (ou avessas às incertezas provocadas pelas revoluções). Esse conjunto de prognósticos ficou conhecido como Teoria da Modernização.

Não obstante as acentuadas diferenças teóricas entre a escola institucionalista dahlsiana e os teóricos da modernização, constata-se em ambas o conceito de competição política como base dos sistemas democráticos. Tanto em Dahl (1997) quanto em Lipset (Lipset, 1959), a competição política é um dos requisitos para que um sistema seja considerado democrático. Em outras palavras, por mais dissenso existente acerca das explicações de como se estabelece a competição, esta será um atributo definidor do que é um sistema democrático.

O país comemorou recentemente duas décadas da promulgação da Constituição de 1988. Na perspectiva histórica, 20 anos pode parecer um período relativamente curto. Entretanto, intensas transformações marcaram profundamente as estruturas sociais, políticas e econômicas brasileiras. A descentralização político-administrativa, sem sombra de dúvidas, é uma das principais marcas desse período. O incremento da autonomia das unidades locais foi seguido de uma intensa e abrupta criação de unidades administrativas municipais. Entre 1988 e 2001, foram criados nada menos do que 1439 novos municípios - ou aproximadamente duas unidades a cada semana! Compreender o Brasil de hoje é uma tarefa impossível sem analisar as características socioeconômicas e políticas destas unidades federativas. 
Em resposta ao período de extrema centralização político-administrativa da ditadura militar, criou-se um forte movimento no Brasil pela descentralização, que visava retirar tudo o que fosse atribuído ao regime anterior - instituições ficaram conhecidas "por entulho autoritário". No momento seguinte à queda da autocracia militar brasileira, descentralização se tornou sinônimo de democratização. Este movimento teve grande parte de suas demandas atendidas e decantadas na Constituição de 1988. Aos municípios foi atribuída uma série de responsabilidades de provimento de políticas públicas, assim como repasses constitucionais de recursos tributários.

As consequências da referida descentralização tributária, promovida pela Constituição de 1988, ficam evidentes na comparação longitudinal das participações das receitas dos entes federados. Afonso; Araújo (2000) detectaram um impressionante crescimento das receitas municipais entre 1989 e 1999. Segundo os autores, os municípios aumentaram suas receitas em 197\%, passando de R\$ 4.917 milhões para R\$ 14.625 milhões, enquanto a União teve um incremento de 54,8\% (de R\$ 121.303 milhões para R\$ 187.733 milhões) e os Estados de 63,9\% (de R\$ 44.625 milhões para R\$ 73.178 milhões). ${ }^{2}$

Embora o crescimento das receitas municipais seja explicado em parte pelos tributos como o ISS (Imposto sobre venda de serviços), IPTU (Impostos sobre propriedade territorial urbana) e demais taxas instituídas pelos próprios municípios, os principais responsáveis pela crescente participação dos municípios na distribuição dos recursos tributários são de fato os repasses constitucionais oriundos tanto da União quanto dos Estados.

Apesar do ótimo desempenho da arrecadação direta municipal desde a Constituição de 1988, revertendo a centralização promovida pela reforma de 1965/67 e levando uma participação relativa no "bolo" tributário superior à observada no início dos anos 60, os municípios arrecadam apenas 5,3\% de todos os tributos cobrados no país, aí incluídas as contribuições sociais. Para atingir o atual patamar de 17\% da receita tributária disponível, as participações municipais na receita de impostos federais e estaduais ainda são preponderantes (Afonso and Araújo, 2000).

Em grande medida, as transferências governamentais constitucionais foram criadas para amenizar as enormes desigualdades regionais e acabaram por incentivar a criação de novos municípios. O Fundo de Participação dos Municípios (FPM), por exemplo,

2 Ver (Afonso \& Araújo, 2000) p: 21 (tabela 2). 
representa uma importante fonte de receita dos municípios e tem como princípio de distribuição o fator demográfico.

Não é demais acrescentar que o FPM representa, por um lado, a primeira fonte de financiamento para a grande maioria das prefeituras, por outro, tem uma relevância inversamente proporcional ao tamanho do município. Nos últimos anos, as regras de repartição do FPM incentivaram a proliferação de centenas de novas unidades municipais, na maioria dos casos muito pequenas e sem a menor condição de se sustentarem sem os repasses do governo federal (Afonso \& Araújo, 2000).

São inegáveis, portanto, os incentivos à criação de municípios instituídos pela descentralização tributário-administrativa. Não obstante, escapam aos analistas outros incentivos de ordem política, a saber, juntamente com a criação de novos municípios surgem novas câmaras municipais. No Brasil, os municípios são os menores distritos eleitorais e, no seu conjunto, são responsáveis pelo maior número de representantes eleitos, pois são mais 5.560 municípios com magnitudes variando entre nove (9) e cinquenta e cinco (55) nas eleições proporcionais (vereadores). Imagine, por exemplo, que um município com 9.000 habitantes, que eleja 9 vereadores, será desmembrado em dois outros do mesmo tamanho. A relação entre representantes e representados, que era de um vereador para cada mil eleitores, passará a ser de um para cada 500. Com isso, automaticamente também diminui o quociente eleitoral para os partidos ${ }^{4}$.

3 Em dezembro de 2008, o Senado Federal aprovou uma Proposta de Emenda à Constituição (PEC) que altera o número de vereadores nos municípios, aumentando o número para 59.267 cadeiras. Esta foi uma resposta do Senado à uma resolução do TSE (Resolução no 21.702, de 2 de abril de 2004), que reduziu o número de vereadores em 159 municípios. Foi esta resolução de 2004 do STF que vigorou nas eleições municipais de 2008.

4 Até a instituição da Lei complementar que regulamentou o cálculo do FPM para os novos municípios, a divisão representava um jogo de soma quase zero. 
Tabela 1: Proporção de municípios, eleitores e vereadores por tamanho do eleitorado

\begin{tabular}{|c|c|c|c|c|c|c|c|}
\hline \multirow{2}{*}{$\begin{array}{l}\text { Tamanho do } \\
\text { eleitorado } \\
2012\end{array}$} & \multicolumn{2}{|c|}{ Municípios } & \multicolumn{2}{|l|}{ Vereadores } & \multicolumn{3}{|l|}{ Eleitores } \\
\hline & $\mathbf{N}$ & $\begin{array}{l}\% \text { Total de } \\
\text { Municípios }\end{array}$ & $\begin{array}{c}\text { Total de } \\
\text { Vereadores }\end{array}$ & $\begin{array}{l}\% \text { Total de } \\
\text { Vereadores }\end{array}$ & Média & $\begin{array}{l}\text { Total de } \\
\text { Eleitores }\end{array}$ & $\begin{array}{c}\% \text { Total de } \\
\text { Eleitores }\end{array}$ \\
\hline Até 5.000 & 1.620 & 29,10 & 14.580 & 25,4 & $3.351,4$ & 5.432 .631 & 3,9 \\
\hline De 5.001 a 10.000 & 1.481 & 26,59 & 13.369 & 23,3 & $7.155,9$ & 10.597 .957 & 7,5 \\
\hline $\begin{array}{l}\text { De } 10.001 \text { a } \\
20.000\end{array}$ & 1.267 & 22,75 & 12.881 & 22,4 & $14.109,1$ & 17.876 .174 & 12,7 \\
\hline $\begin{array}{l}\text { De } 20.001 \text { a } \\
50.000\end{array}$ & 774 & 13,90 & 9.353 & 16,3 & $29.917,8$ & 23.156 .377 & 16,5 \\
\hline $\begin{array}{l}\text { De } 50.001 \text { a } \\
100.000\end{array}$ & 240 & 4,31 & 3.414 & 5,9 & $68.376,8$ & 16.410 .430 & 11,7 \\
\hline $\begin{array}{l}\text { De } 100.001 \text { a } \\
200.000\end{array}$ & 103 & 1,85 & 1.773 & 3,1 & $141.180,4$ & 14.541 .586 & 10,4 \\
\hline Mais de 200.001 & 83 & 1,51 & 2.037 & 3,5 & $623.558,9$ & 52.378 .948 & 37,3 \\
\hline Total & 5.568 & 100,00 & 57.407 & 100,00 & & 140.394 .103 & 100,0 \\
\hline
\end{tabular}

Fonte: Dados calculados pelo autor com base no TSE.

Não obstante a grande evolução da ciência política brasileira nas análises do sistema político nacional, pouca atenção tem sido dada aos sistemas locais. A esmagadora maioria dos trabalhos científicos sobre política brasileira atualmente foca suas análises primordialmente no cenário nacional. Diagnósticos sobre o sistema político brasileiro que negligenciam a política municipal correm sérios riscos de cometer falácias de desagregação (ou de divisão, aquela que toma as partes pelo todo). Exemplo pode ser encontrado em Nicolau (1996), ao analisar as motivações para a formação de coligações: o fato de ser um grande partido na Câmara dos Deputados não significa que assim o seja em todas as unidades da federação. O mesmo havia apontado Lima Jr. (1983) acerca dos subsistemas estaduais, cada qual com sua própria lógica e respondendo a estímulos institucionais diferentes, tal como as magnitudes dos distritos. Toda e qualquer análise acerca da distribuição do sistema partidário nacional, portanto, deveria partir de análises dos Estados exatamente pelo efeito de agregação provocado pelo sistema eleitoral, que tem nestes as delimitações dos distritos eleitorais.

Santos e Guimarães (no prelo) descem mais ainda no nível de análise e transportam esse argumento para os sistemas locais, chegando até a concluir, ao contrário do que se apregoa nos noticiários nacionais, um robusto crescimento das pequenas legendas nos 
municípios brasileiros e a absoluta falta de critério para condenar a priori estes partidos como ilegítimos (partidos de aluguéis) no cenário onde atuam:

O pessimismo de semelhantes prognósticos é bastante questionável, em particular o do presumido contagio institucional, segundo o qual os partidos ditos "de aluguel" representam estadualmente e municipalmente o mesmo que representariam a nível nacional, isto é, praticamente nada (Santos \& Guimarães, no prelo, pp. 13-14).

\section{Sistemas partidários e número de partidos}

A distinção entre os sistemas partidários democráticos foi muito influenciada pela obra magistral de Maurice Duverger, Os partidos políticos, publicada na década de 1950, em que o autor distingue dois principais sistemas, quais sejam, os bipartidários e os multipartidários. Segundo Duverger (1980), as tendências políticas se apresentam na forma dualista, por este motivo o movimento natural das sociedades seria orientado para o bipartidarismo, "com isso se quer dizer que as opções políticas se apresentam, comumente, sob a forma dualista. Nem sempre há dualismo de partidos, mas quase sempre há dualismo de tendência". Mas o que explicaria a existência do multipartidarismo? 0 multipartidarismo seria, então, explicado pela superposição de dualismo e pelo fracionamento de opiniões de um partido. O primeiro motivo significa a não coincidência de oposições dualistas, ou seja, duas oposições como católicos $X$ protestantes e esquerda $X$ direita poderiam formar quatro diferentes partidos como católicos-esquerdistas, católicos-direitistas, protestantes-esquerdistas e protestantes-direitistas. O segundo motivo poderia acontecer caso houvesse a radicalização de uma das facções do partido criando uma outra oposição, como moderados X extremistas, por exemplo. Duverger não explica, no entanto, como contar o número de partidos existentes, o que pode trazer grandes dificuldades nos estudos comparados.

Outras tipologias dos sistemas partidários foram criadas levando em consideração fatores diversos dos analisados por Duverger, como a força obtida pelos partidos nas eleições. Jean Blondel, em 1990, observa a votação média dos dois maiores partidos para classificar o sistema de acordo com o desempenho eleitoral dos partidos, desta forma, os sistemas bipartidários seriam aqueles onde os dois maiores partidos somam 
mais de $90 \%$ dos votos, nos sistemas de dois partidos e meio os dois maiores devem somar entre 75\% e 80\%. Além de possuir um terceiro partido com votação bem menor, os sistemas multipartidários com partido predominante têm a soma dos dois maiores partidos perto de $75 \%$ e com um partido angariando cerca de $40 \%$ dos votos. Já nos sistemas multipartidários sem partido predominante os dois maiores conquistam aproximadamente $50 \%$ dos votos.

Giovanni Sartori (1996) retoma os conceitos clássicos de Duverger, porém, fundamenta sua contagem dos partidos através do conceito de "partido relevante" (Relevant Party). No intuito de suprimir as falhas de Duverger, os "partidos relevantes" são assim considerados através de dois fatores, quais sejam, a potencialidade de coalizão (regra no 1) e a potencialidade de chantagem (regra $n \circ 2$ ). A primeira regra se refere aos partidos que se orientam em favor do governo ou são aceitáveis pelos outros membros da coalizão, a segunda faz referência aos partidos da oposição ou ideologicamente incompatíveis com o governo.

Regra no 1: Um partido menor pode ser considerado irrelevante quando continua a ser supérfluo ao longo do tempo - no sentido de que nunca é considerado necessário ou é utilizado para compor uma maioria de coalizão. Inversamente, um partido menor deve ser contado como relevante, por menor que seja, se ele se encontra na posição de determinar ao longo do tempo, ou em algum momento, pelo menos uma das possíveis maiorias governamentais.

Regra no 2: Um partido é relevante quando a sua existência, ou o seu surgimento, afeta a tática da competição partidária, e particularmente quando altera o sentido da competição - para a esquerda, para a direita ou nos dois sentidos - dos partidos que se orientam em favor do governo.

O critério realmente decisivo da contagem de partidos para Sartori é a influência no jogo parlamentar: os partidos que não influenciarem na constituição da coalizão de governo ou na composição da oposição, ou seja, os partidos que não estivessem em condição de influenciar o exercício do poder não seriam contabilizados.

Contudo, o critério numérico não basta para Sartori, este seria apenas o primeiro passo. Depois de contabilizado os partidos - através das duas regras acima -, devem ser levadas em consideração as suas posições ideológicas no eixo direita-esquerda, assim "é evidente, portanto, que há algo que a contagem não pode identificar e que, não 
obstante, é essencial. Isso equivale a dizer que temos, necessariamente, de passar da classificação para a tipologia e, com isso, complementar o critério numérico tomando a ideologia como critério".

A partir desses dois critérios - fragmentação (formato) e polarização ideológica (distância dos partidos no eixo direita-esquerda) -, Sartori distingue dois modelos de multipartidarismo. São eles: pluralismo moderado (alta fragmentação com baixa polarização) e pluralismo polarizado (alta fragmentação com alta polarização).

Mas uma pergunta ainda não foi respondida: qual é, ou quais são, a(s) causa(s) responsáveis pelo formato do sistema partidário? Mais importante para nós ainda é responder que fatores contribuem ou obstruem a formação de um sistema multipartidário.

A tese mais defendida tem sido a dos efeitos dos sistemas eleitorais que recaem sobre os sistemas partidários, precisamente sobre o número de partidos. As contribuições mais discutidas foram chamadas "Leis de Duverger".

Mesmo considerando que somente análises próprias de cada país poderiam determinar as fontes dos sistemas partidários, Duverger defende a influência de um fator geral de "ordem técnica", qual seja, o sistema eleitoral. Desta forma, elabora duas proposições básicas:

1 - o escrutínio majoritário de um só turno tende ao dualismo dos partidos;

2 - o escrutínio majoritário de dois turnos ou a representação proporcional tende ao multipartidarismo.

Após muitos testes as "Leis de Duverger" sofreram algumas importantes modificações, seja por outros estudos que incluíram as exceções, seja por outros testes que tentaram negá-las totalmente.

Mais específico foi o estudo de Jairo Marconi Nicolau em Multipartidarismo e democracia, em que o autor examina o impacto da estrutura institucional sobre o sistema partidário brasileiro e analisa as principais causas responsáveis pelo grande número de partidos no sistema brasileiro, tais como: a legislação eleitoral (1982-1995), que permitiu aos partidos com registro provisório participarem das eleições apresentando candidatos ; a troca de legenda dos líderes partidários no período intereleições, que favoreceu a criação de novos partidos; a alta magnitude (M) dos distritos, que facilita a conquista 
de cadeiras pelos partidos menores; a possibilidade de coligação eleitoral, permitindo que os partidos se unam nas eleições e funcionem como sendo apenas um, no cálculo eleitoral.

Por outro lado, Nicolau defende que a fórmula eleitoral D'Hondt, utilizada para a transformação dos votos em cadeiras parlamentares, pelo fato de ser muito desproporcional, é responsável pelo favorecimento dos maiores partidos e, por conseguinte, funciona como uma cláusula de exclusão. Este quadro ainda é agravado por dois fatores, primeiro pela inclusão dos votos em branco no cálculo do quociente eleitoral, o que pressiona para cima o número mínimo de votos necessário para um partido conquistar a primeira cadeira e, segundo, a exclusão dos partidos que não atingiram o quociente eleitoral na distribuição das sobras - isto explica que, apesar de muitos partidos participarem das eleições, poucos se transformaram em partidos parlamentares. Em resumo, a alta fragmentação do sistema partidário brasileiro não é causada pelo sistema eleitoral brasileiro, pois este privilegia os maiores partidos.

\section{Dispersão das forças eleitorais nos municípios brasileiros}

Há diversas formas de se mensurar a competitividade dos sistemas: dos mais simples aos mais complexos, cada indicador busca captar uma das dimensões do conceito. Não é raro encontrar análises jornalísticas que confundem o real significado de cada indicador e acabam por interpretar equivocadamente os fenômenos que se pretende compreender. Por este motivo, vale a pena dedicar algumas linhas para clarificar os indicadores que aqui serão utilizados.

Talvez o indicador mais comum na literatura especializada que se lança na empreitada de mensurar a competitividade dos sistemas seja o número efetivo de partidos, que foi criado por Laakso e Taagepera (1979) a partir do índice de fracionalização de Rae. ${ }^{5}$ Este indicador tem como objetivo estabelecer o nível de fragmentação das forças

5 Em realidade, o indicador proposto por Douglas Rae é uma adaptação do conhecido índice de Herfindahl-Hirschman $(\mathrm{H}-\mathrm{H})$, amplamente utilizado na economia para mensurar dispersão-concentração de indústrias e mercados. Para maiores detalhes sobre os índices mais utilizados na ciência política e seus limites, ver Nicolau (1997). Michael Gallagher em sua página na internet disponibiliza arquivos em excel que fornecem formas simples de se calcular uma série de indicadores, basta o usuário inserir os dados que o programa calcula automaticamente, ver: http://www.tcd.ie/Political_Science/staff/ michael_gallagher/EISystems/index.php. 
competitivas. Por mais que tenha sido demasiadamente utilizado pela literatura, vale um nota a respeito do cálculo e das interpretações destes indicadores.

O índice fracionalização $(F)$ é calculado pela fórmula $F=1 / \sum v^{2}$, em que vi é a proporção obtida por cada partido. $O$ indicador pode variar entre 0 e 1, e sua interpretação é bastante simples: dada uma determinada distribuição de votos entre os partidos, quanto maior for a fracionalização, maior a probabilidade de se escolher ao acaso (aleatoriamente) dois votos e de eles pertencerem a partidos diferentes. Se o indicador for igual a zero (0), siginifica que um único partido conquistou todos os votos, ou seja, não há competição; no lado oposto, se o indicador for igual a um (1), cada voto foi dado a um partido diferente, ou seja, competição absoluta. O auxílio de um exemplo torna a compreensão um tanto mais intuitiva.

Imagine uma situação hipotética na qual concorrem cinco partidos com as seguintes proporções de votos cada: o partido A obteve 20\%, B 40\%, C 5\%, D 1\%, E 4\% e F 30\%; assim temos: $F=1-\left[(0,2)^{2}+(0,4)^{2}+(0,05)^{2}+(0,01)^{2}+(0,04)^{2}+(0,3)^{2}\right]$

$$
F=1-0,29=0,71
$$

Neste caso hipotético acima, a chance de escolhermos dois votos e eles pertencerem a partidos diferentes é igual a 79\%, ou a probabilidade de 0,79. Após este exemplo fica mais simples compreender o real significado do indicador número efetivo de partidos (Nep), posto que este é simplesmente uma transformação daquele. O Nep é dado por $1 / \sum \mathrm{vi}^{2}$, em que vi também representa a proporção de votos obtida por cada partido. Então, segue-se que: Nep = 1/ (1 - F). Para utilizar novamente o caso hipotético, o Nep seria igual a 1/(0,29), ou seja, 3,45. Ao contrário do índice de fracionalização, o número efetivo de partidos não possui uma interpretação substantiva. Entretanto, sua utilização se tornou muito mais comum. ${ }^{6}$

Como já afirmado anteriormente, os sistemas partidários nos municípios podem ser bastante distintos do sistema nacional, cabe investigar em que grau está e como foi a evolução da competição eleitoral nos sistemas municipais. Vejamos mais detidamente o fenômeno da competição eleitoral e sua recente evolução. Nas últimas cinco eleições municipais (1996, 2000, 2004, 2008 e 2012), os indicadores de Número Efetivo

6 Quiçá a tradução do inglês (effective number of parties) e a altíssima ressonância do termo deste indicador tenham provocado interpretações equivocadas. A principal delas é o chamado "equívoco de retorno", ou seja, o leitor interpreta o indicador agregado (por exemplo, Nep = 3) e retorna à distribuição dos votos acreditando ser os três maiores partidos realmente efetivos. Em realidade, o que é efetivo é o número, e não o partido. O indicador é simplesmente uma construção abstrata de uma probabilidade. 
de Partidos (NEP) têm demonstrado uma crescente competição eleitoral no nível municipal. O Gráfico 1 demonstra as médias do NEP para as quatro eleições municipais, tanto para as majoritárias quanto para as proporcionais. Observa-se um crescimento contínuo da competição das eleições proporcionais e uma aparente estabilidade nas eleições majoritárias.

Gráfico 1: Número efetivo de partidos nos municípios (1996-2012)

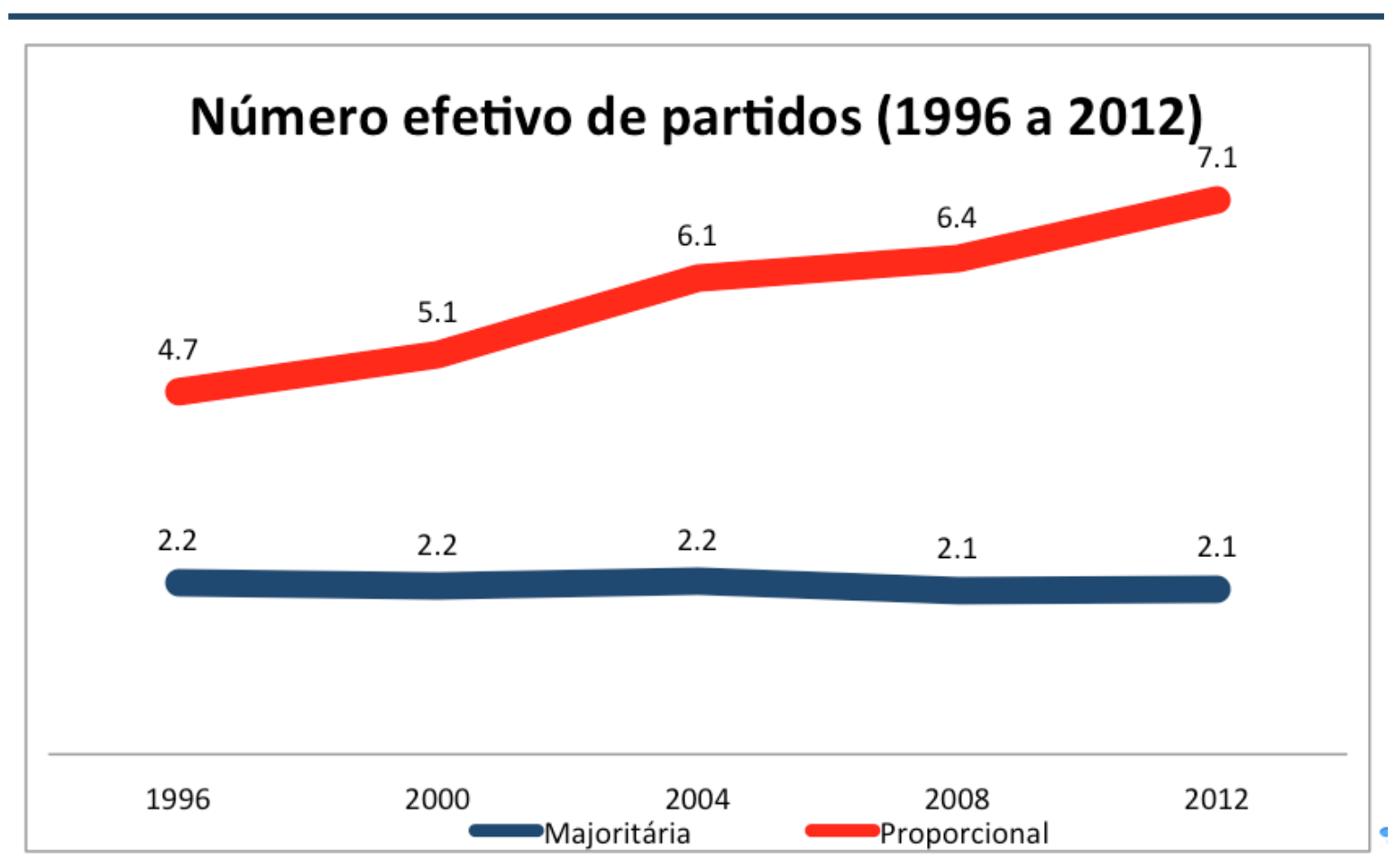

Fonte: Dados calculados pelo autor com base no TSE.

Como se observa na tabela abaixo, existem fortes indícios de que o número efetivo de partidos para eleições proporcionais tem crescido nos municípios em decorrência não somente de uma fragmentação das forças eleitorais já existentes, mas, sobretudo, pela introdução de novos atores na competição. Em geral, percebe-se um aumento significativo do número de municípios, em que os partidos lançam candidatos, com exceção dos grandes partidos nacionais como PMDB, PSDB, DEM/PFL nas eleições majoritárias.7 Nas eleições proporcionais, quase todos os partidos aumentam o número de municípios que participam lançando candidatos, principalmente os pequenos partidos

7 Para as eleições majoritárias foi considerado apenas o candidato a prefeito da coligação. A rigor, isto não significa necessariamente que um partido ao lançar o candidato a vice-prefeito não tenha participado das eleições, mas que participou como coadjuvante. 
como PSB, PV, PDT, PSC e PC do B. Este aumento do número de atores, com especial destaque para o PT e pequenos partidos, e da fragmentação de forças podem ser observados para todas as faixas de tamanho da população.

Tabela 2: Número de municípios em que os partidos concorreram nas eleições majoritárias e proporcionais

\begin{tabular}{|c|c|c|c|c|c|c|c|c|c|c|}
\hline \multirow[t]{2}{*}{ PARTIDOS } & \multicolumn{5}{|c|}{ PROPORCIONAIS } & \multicolumn{5}{|c|}{ MAJORITÁRIAS } \\
\hline & 1996 & 2000 & 2004 & 2008 & 2012 & 1996 & 2000 & 2004 & 2008 & 2012 \\
\hline PMDB & 5.003 & 5.241 & 5.161 & 5.211 & 5.206 & 2.997 & 2.838 & 2.485 & 2.653 & 2.269 \\
\hline PT & 2.853 & 3.411 & 5.069 & 4.976 & 5.122 & 1.077 & 1.314 & 1.952 & 1.634 & 1.781 \\
\hline PSDB & 4.229 & 4.536 & 4.651 & 4.711 & 4.648 & 2.186 & 2.073 & 1.924 & 1.777 & 1.625 \\
\hline PSD & $* * * *$ & $* * * *$ & $* * * *$ & $* * * *$ & 4.019 & $* * * *$ & $* * * *$ & $* * * *$ & $* * * *$ & 1.102 \\
\hline PP & 3.820 & 4.189 & 4.357 & 4.275 & 4.457 & 1.574 & 1.407 & 1.268 & 1.205 & 1.078 \\
\hline PSB & 1.399 & 2.010 & 2.689 & 3.519 & 3.960 & 490 & 481 & 621 & 884 & 1.039 \\
\hline PDT & 3.217 & 3.080 & 3.682 & 3.959 & 4.060 & 1.219 & 902 & 859 & 980 & 844 \\
\hline PTB & 2.964 & 3.711 & 4.250 & 4.161 & 4.061 & 1.079 & 1.069 & 1.098 & 1.007 & 824 \\
\hline PFL/DEM & 4.439 & 4.860 & 4.690 & 4.388 & 3.880 & 2.231 & 2.293 & 1.766 & 1.238 & 733 \\
\hline PL/PR & 2.361 & 2.530 & 4.013 & 3.701 & 3.659 & 687 & 601 & 1.040 & 914 & 707 \\
\hline PPS & 820 & 2.620 & 3.411 & 3.170 & 3.012 & 162 & 627 & 894 & 523 & 431 \\
\hline PV & 549 & 772 & 1.842 & 2.496 & 2.878 & 122 & 135 & 294 & 384 & 413 \\
\hline PSOL & $* * * *$ & $* * * *$ & $* * * *$ & 408 & 517 & $* * * *$ & $* * * *$ & $* * * *$ & 280 & 348 \\
\hline PSC & 978 & 1.132 & 1.654 & 2.237 & 2.751 & 260 & 166 & 181 & 248 & 312 \\
\hline PRB & $* * * *$ & $* * * *$ & $* * * *$ & 2133 & 2.524 & $* * * *$ & $* * * *$ & $* * * *$ & 261 & 300 \\
\hline PC do B & 599 & 780 & 1.354 & 1.873 & 2.296 & 51 & 28 & 105 & 193 & 227 \\
\hline PMN & 592 & 657 & 1.235 & 1.302 & 1.409 & 197 & 79 & 153 & 170 & 178 \\
\hline PRP & 714 & 713 & 1.179 & 1.101 & 1.462 & 161 & 78 & 149 & 92 & 134 \\
\hline PHS & 805 & 841 & 1.046 & 1.217 & 1.473 & 14 & 52 & 141 & 96 & 120 \\
\hline PSL & 539 & 783 & 1.279 & 1.419 & 1.847 & 109 & 100 & 125 & 95 & 113 \\
\hline PT do B & 341 & 432 & 858 & 998 & 1.422 & 73 & 48 & 94 & 87 & 107 \\
\hline PRTB & 118 & 433 & 891 & 939 & 1.230 & 22 & 52 & 89 & 96 & 100 \\
\hline PTC & 156 & 231 & 900 & 1.105 & 1.382 & 23 & 29 & 98 & 94 & 90 \\
\hline PSDC & 229 & 527 & 1.087 & 1.075 & 1.254 & 44 & 66 & 128 & 92 & 88 \\
\hline PTN & 110 & 317 & 859 & 1.012 & 1.324 & 19 & 24 & 70 & 96 & 80 \\
\hline PSTU & 82 & 91 & 116 & 71 & 80 & 44 & 48 & 104 & 34 & 60 \\
\hline PPL & $* * * *$ & $* * * *$ & $* * * *$ & $* * * *$ & 566 & $* * * *$ & $* * * *$ & $* * * *$ & $* * * *$ & 49 \\
\hline PCB & 57 & 69 & 165 & 195 & 81 & 10 & 4 & 12 & 40 & 36 \\
\hline PCO & 14 & 14 & 41 & 9 & 5 & 5 & 12 & 34 & 9 & 5 \\
\hline PAN & 96 & 255 & 622 & $* * * *$ & $* * * *$ & 14 & 25 & 43 & $* * * *$ & $* * * *$ \\
\hline PRONA & 135 & 148 & 451 & $* * * *$ & $* * * *$ & 37 & 15 & 37 & $* * * *$ & $* * * *$ \\
\hline
\end{tabular}


Ambos os indicadores (número efetivo de partidos e aumento de municípios que os partidos lançam candidatos) demonstram que o fenômeno da nacionalização dos partidos no âmbito municipal tem ocorrido com certa intensidade. Essa nacionalização é a grande responsável pelo forte incremento da competição eleitoral nos municípios brasileiros, principalmente no que concerne às eleições proporcionais, onde se verificou um aumento gradual em todas as regiões no país, assim como em municípios de todos os tamanhos. Já no que tange às eleições majoritárias, há uma relativa estabilidade do nível de competição, o que pode ser atribuído ao caráter restritivo da regra majoritária, tal como apontada por Durverger (1980) e Sartori (1996). Dito por outras palavras, os sistemas partidários municipais apresentam uma grande evolução do número de competidores nas eleições para vereadores e, ao mesmo tempo, uma enorme estabilidade nas competições para prefeitos.

Nos gráficos seguintes pode-se observar o incremento da competição eleitoral proporcional em todas as regiões e tamanhos dos municípios, assim como a estabilidade da competição para as eleições majoritárias. Chama a atenção, contudo, ao analisar os mapas georeferenciados, os baixos indicadores de competitividade nos municípios da região Sul. Ao contrário do que propagam os analistas políticos sobre os chamados grotões no Norte e Nordeste brasileiro, onde se encontram grande parte dos municípios mais pobres, com altas taxas de mortalidade e índices alarmantes de analfabetismo. As análises descritivas mostram exatamente o oposto, ou seja, é na região Sul que se encontram os municípios com menores taxas de competitividade. 
Número efetivo de partidos nas eleições municipais brasileiras

Gráfico 2: NEP majoritárias por tamanho do município (1996 a 2012)

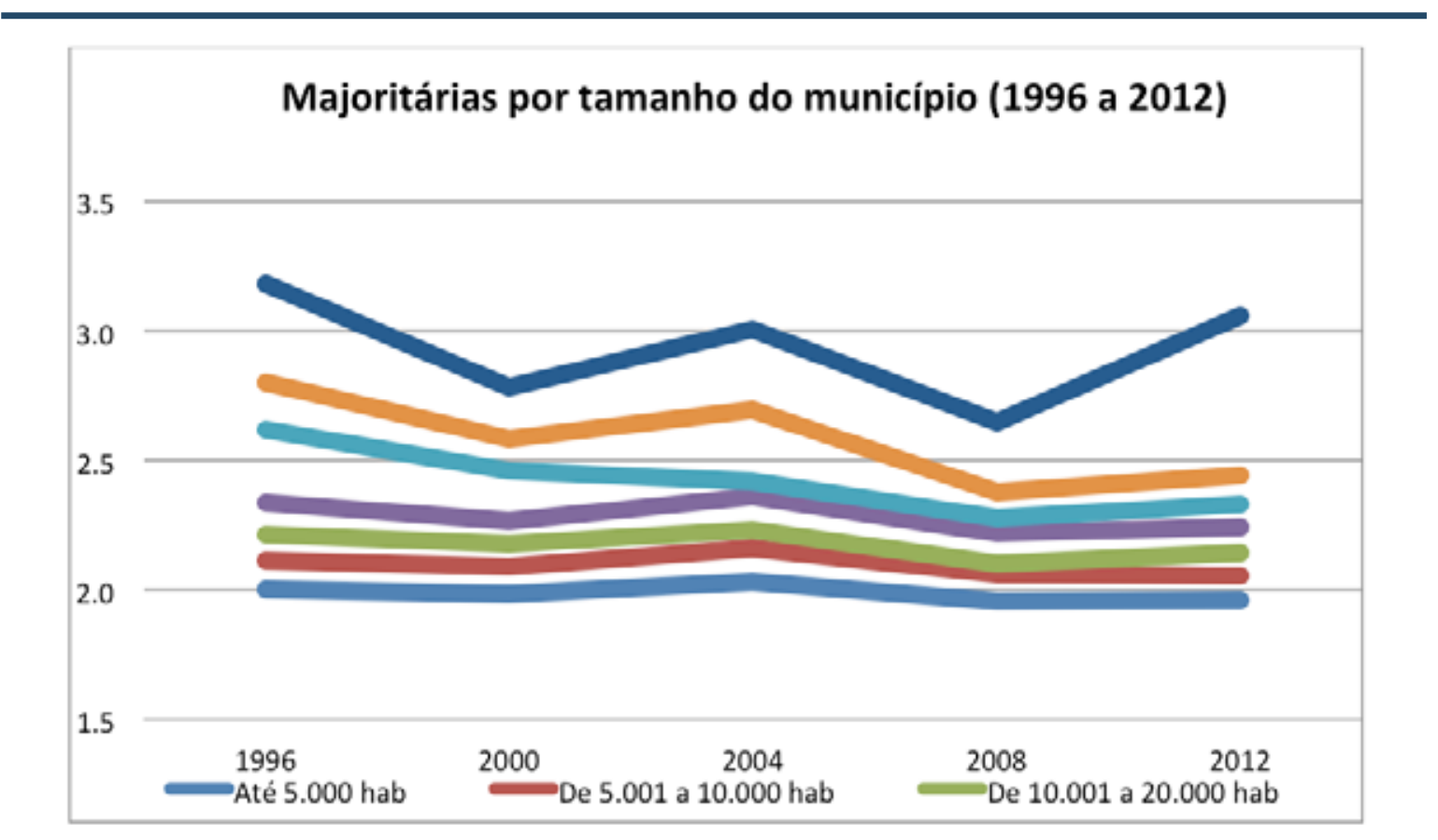

Gráfico 3: NEP proporcionais por tamanho do município (1996 a 2012)

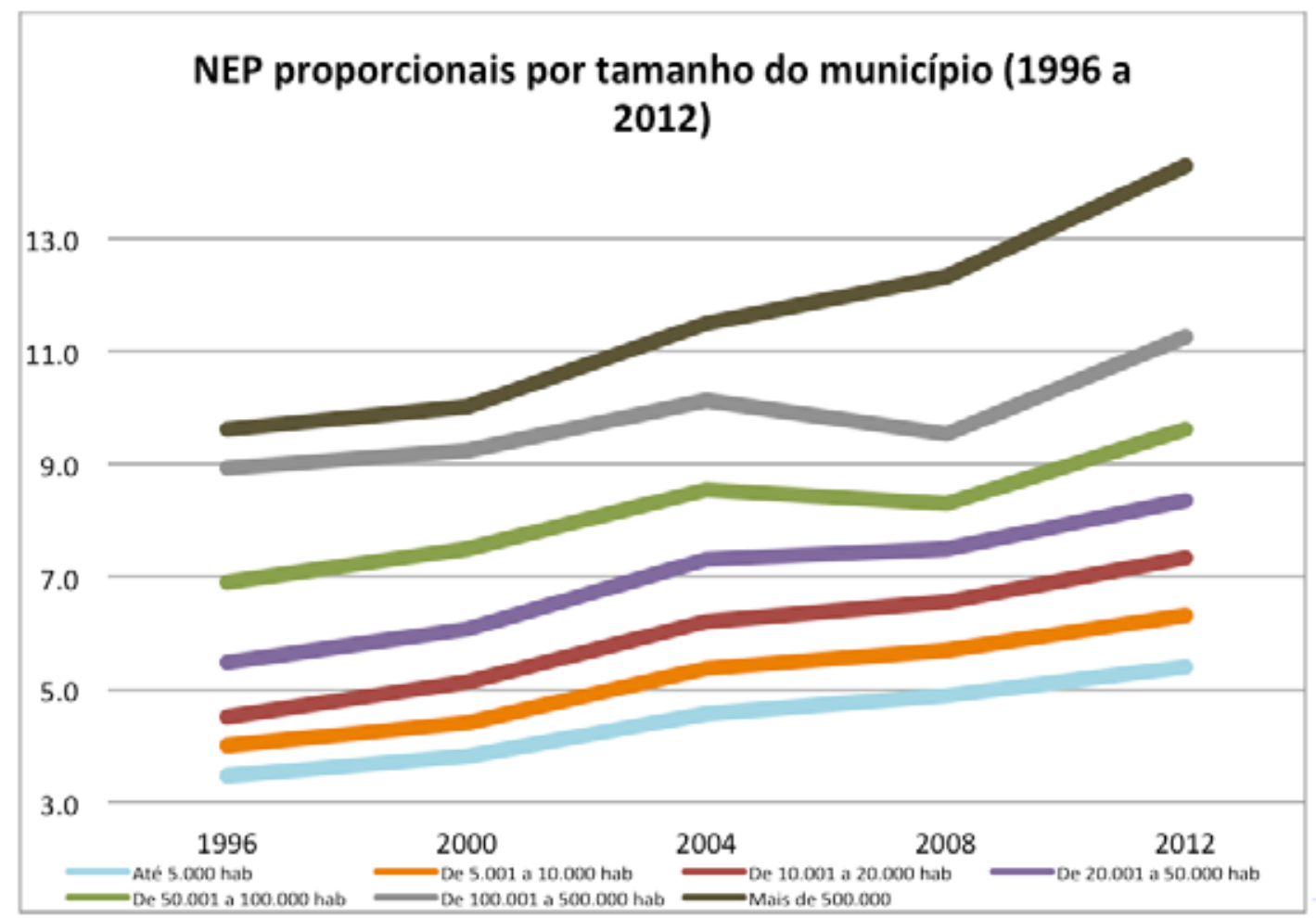


Gráfico 10: NEP majoritárias por região (1996 a 2012)

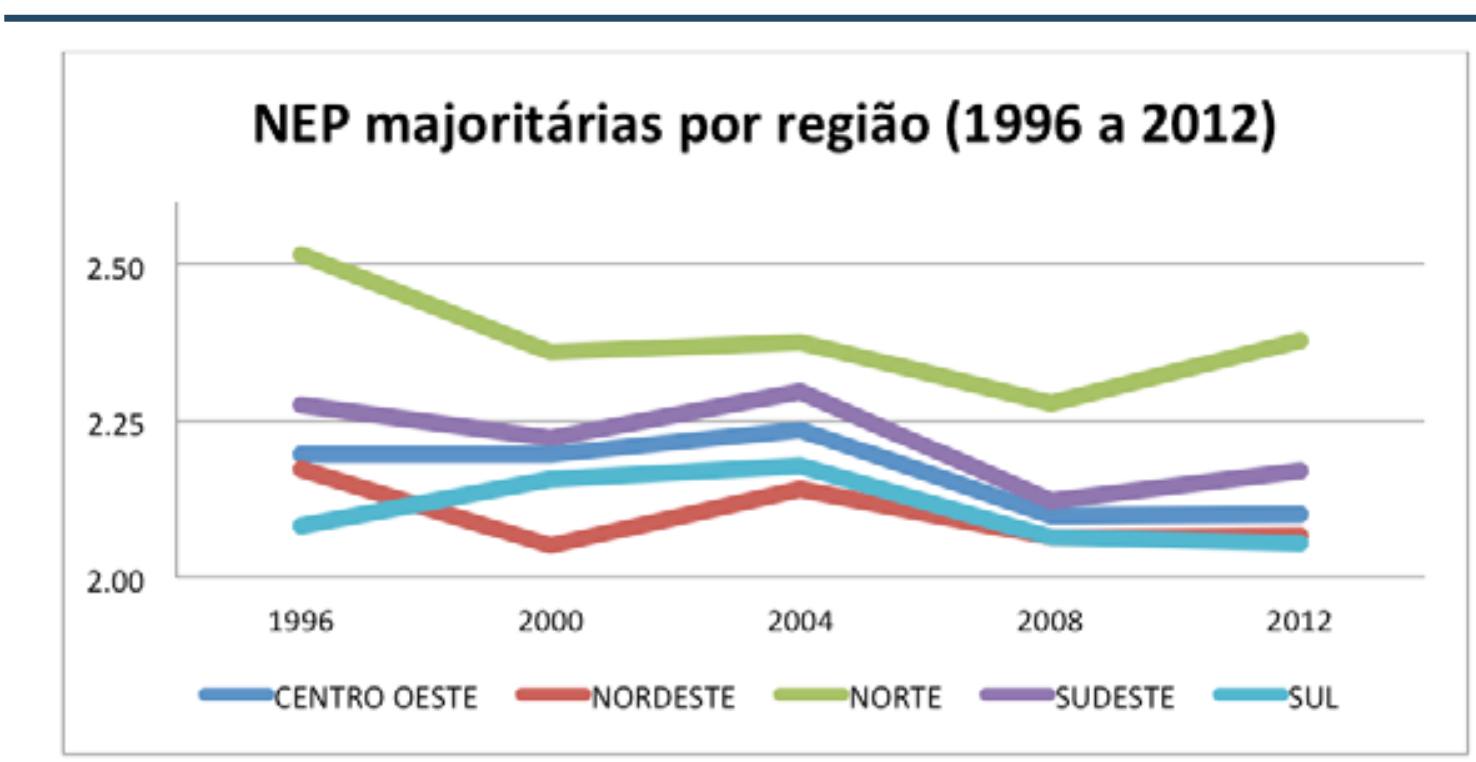

Gráfico 5: NEP proporcionais por região (1996 a 2012)

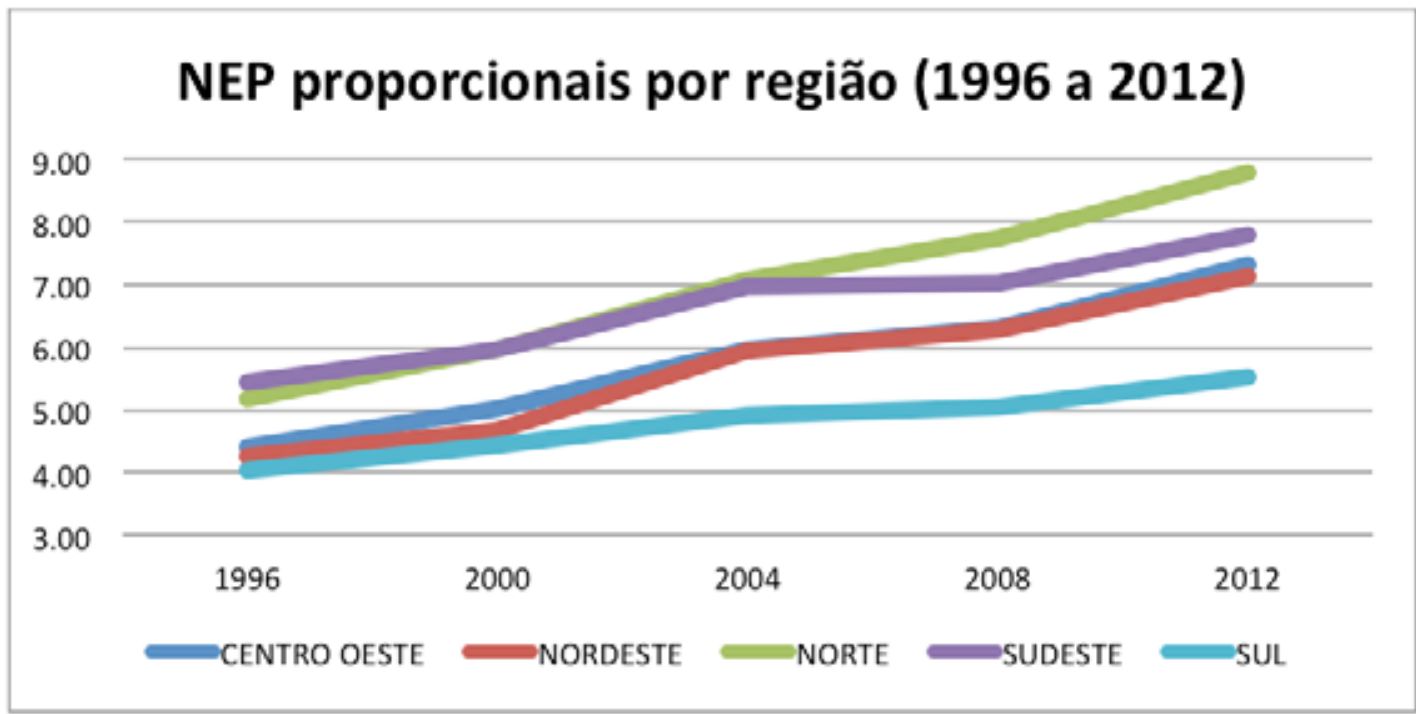




\section{Mapas da competição}
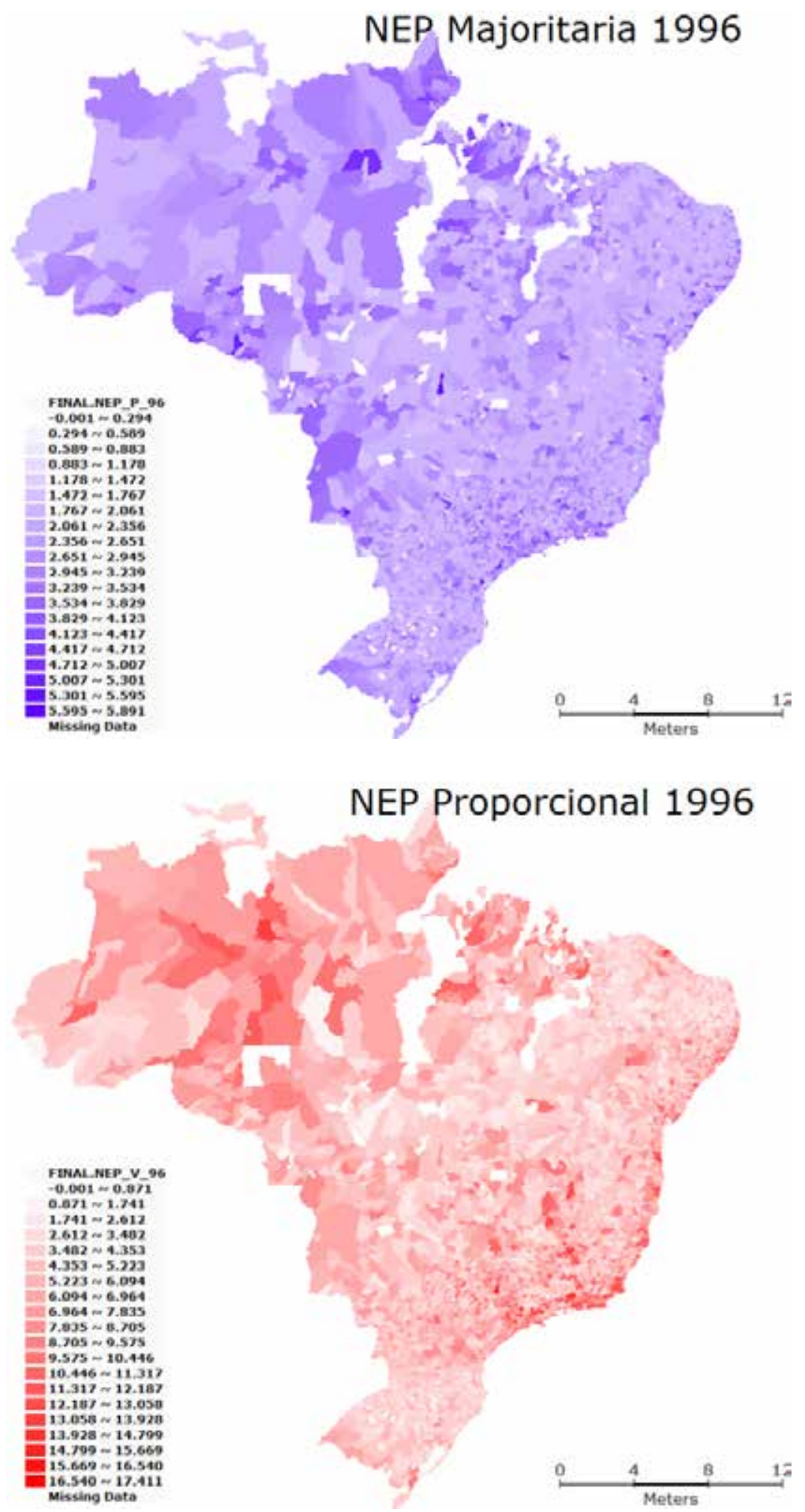

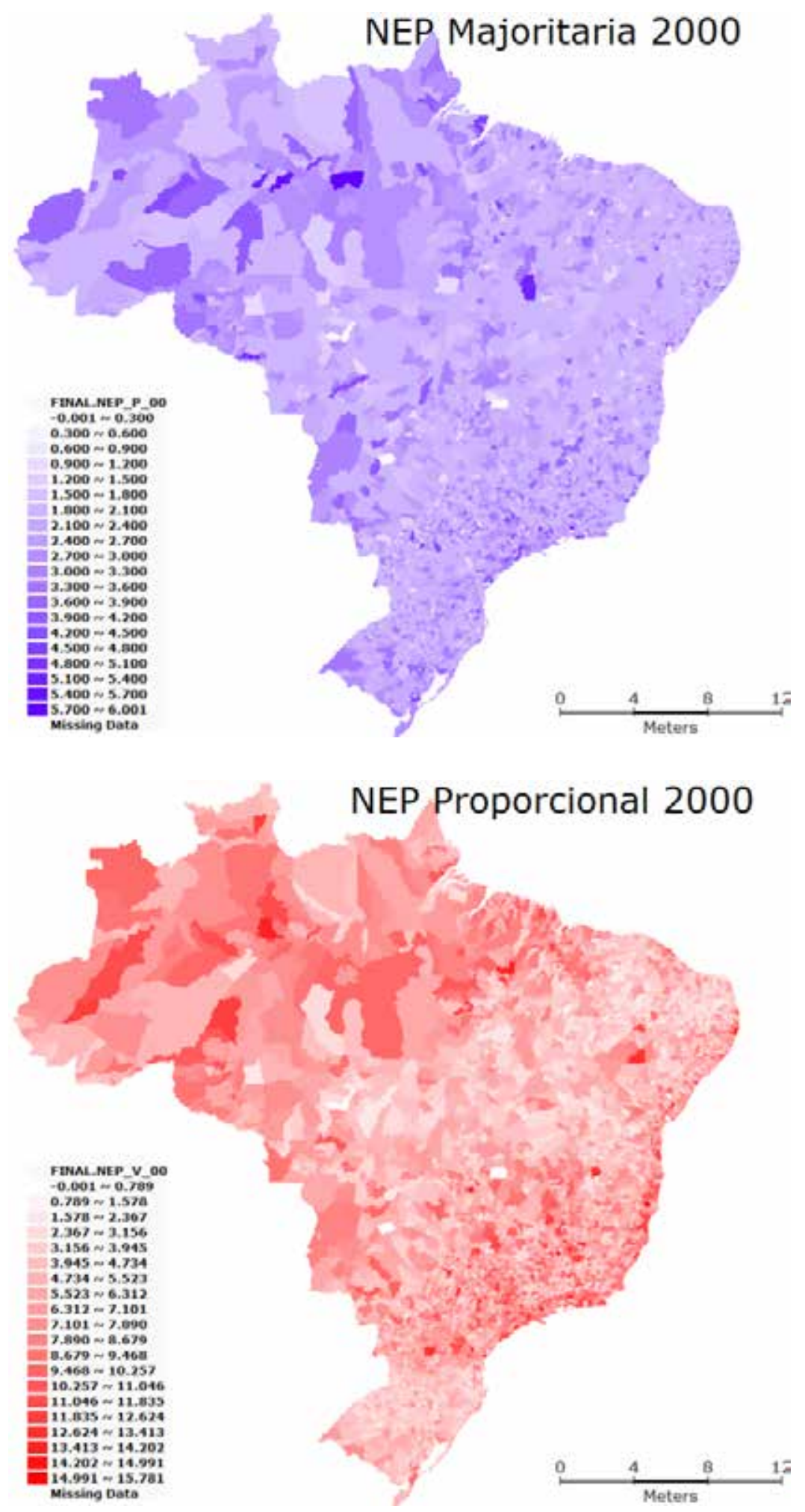

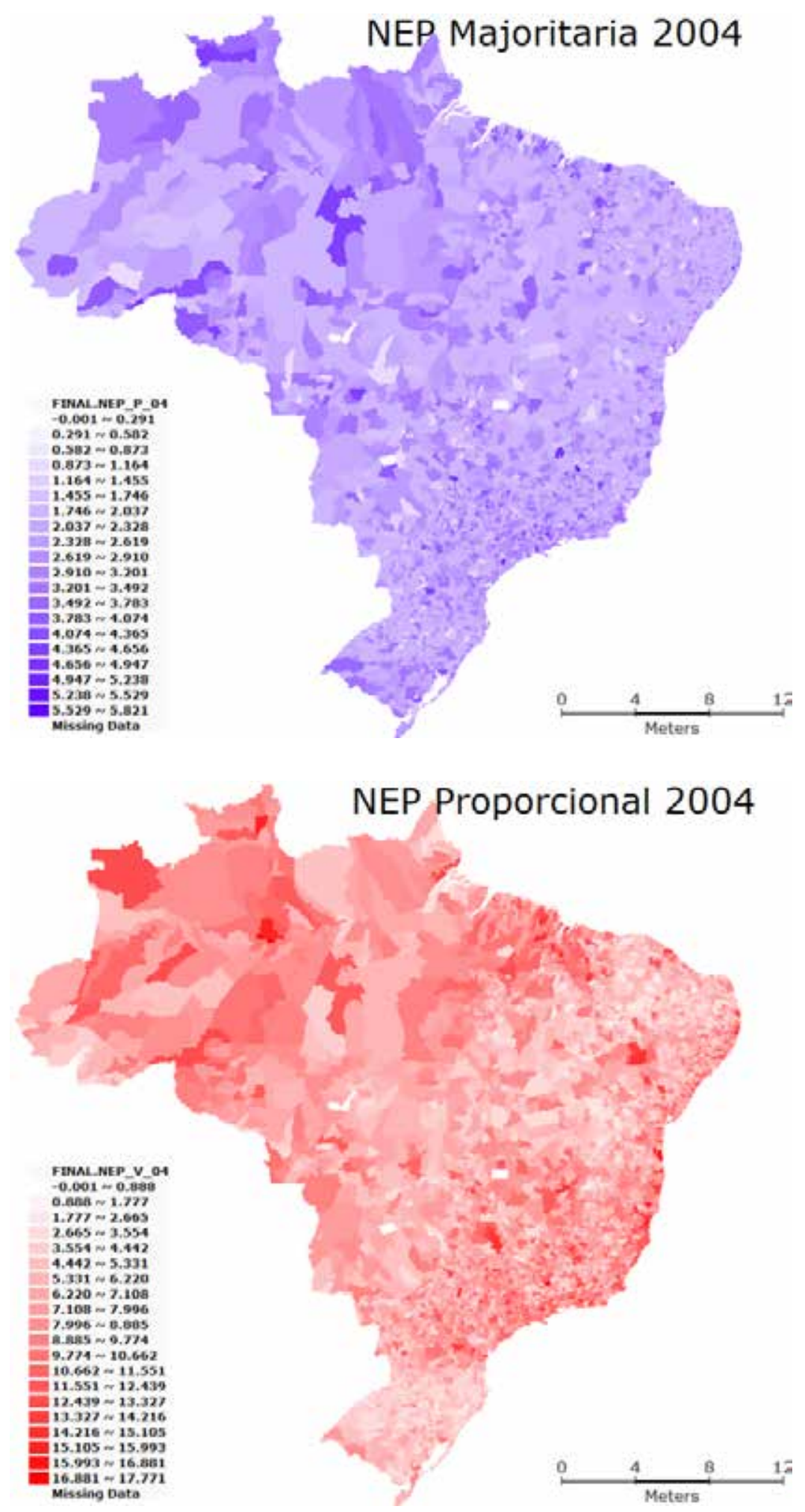

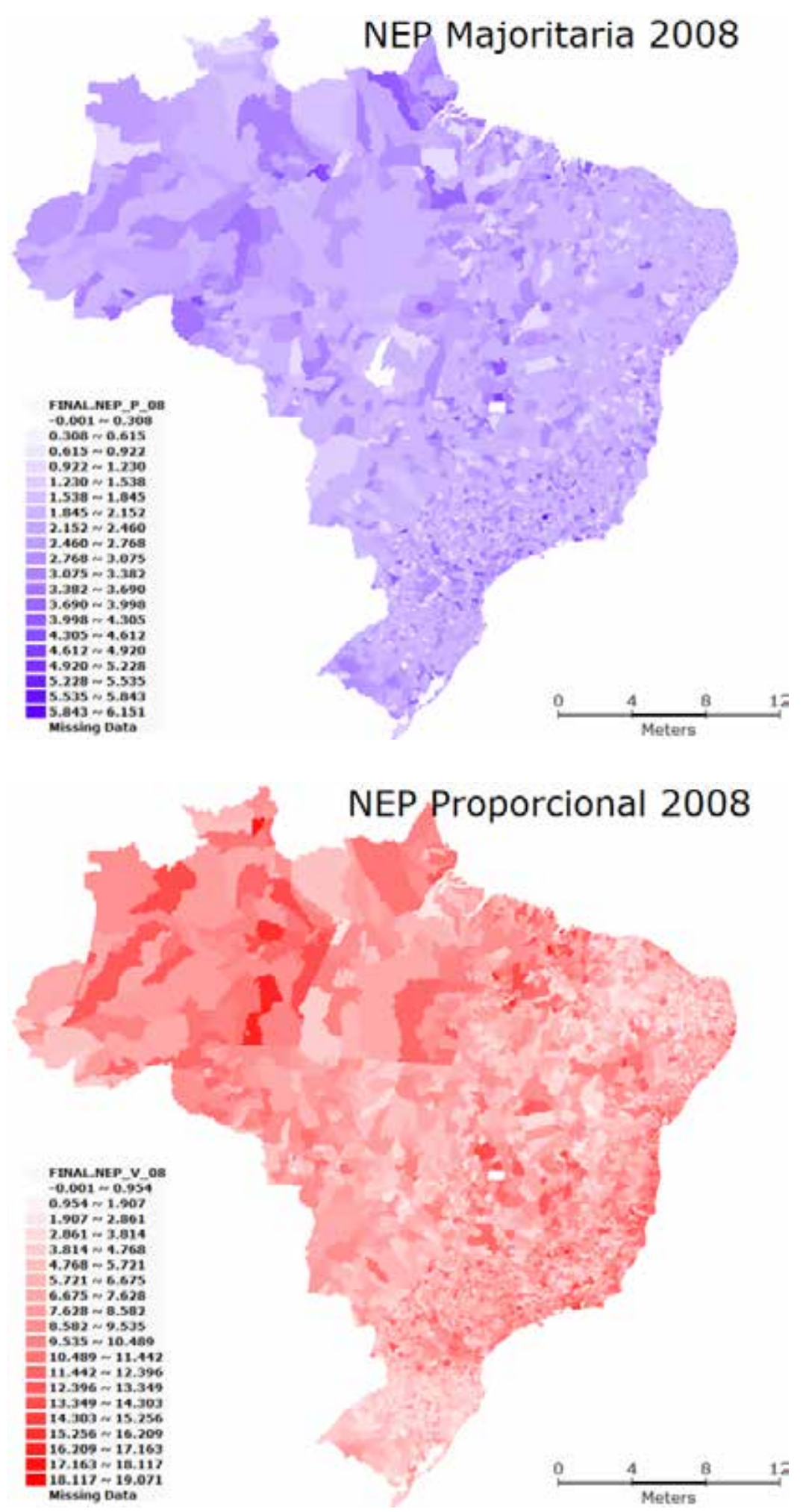

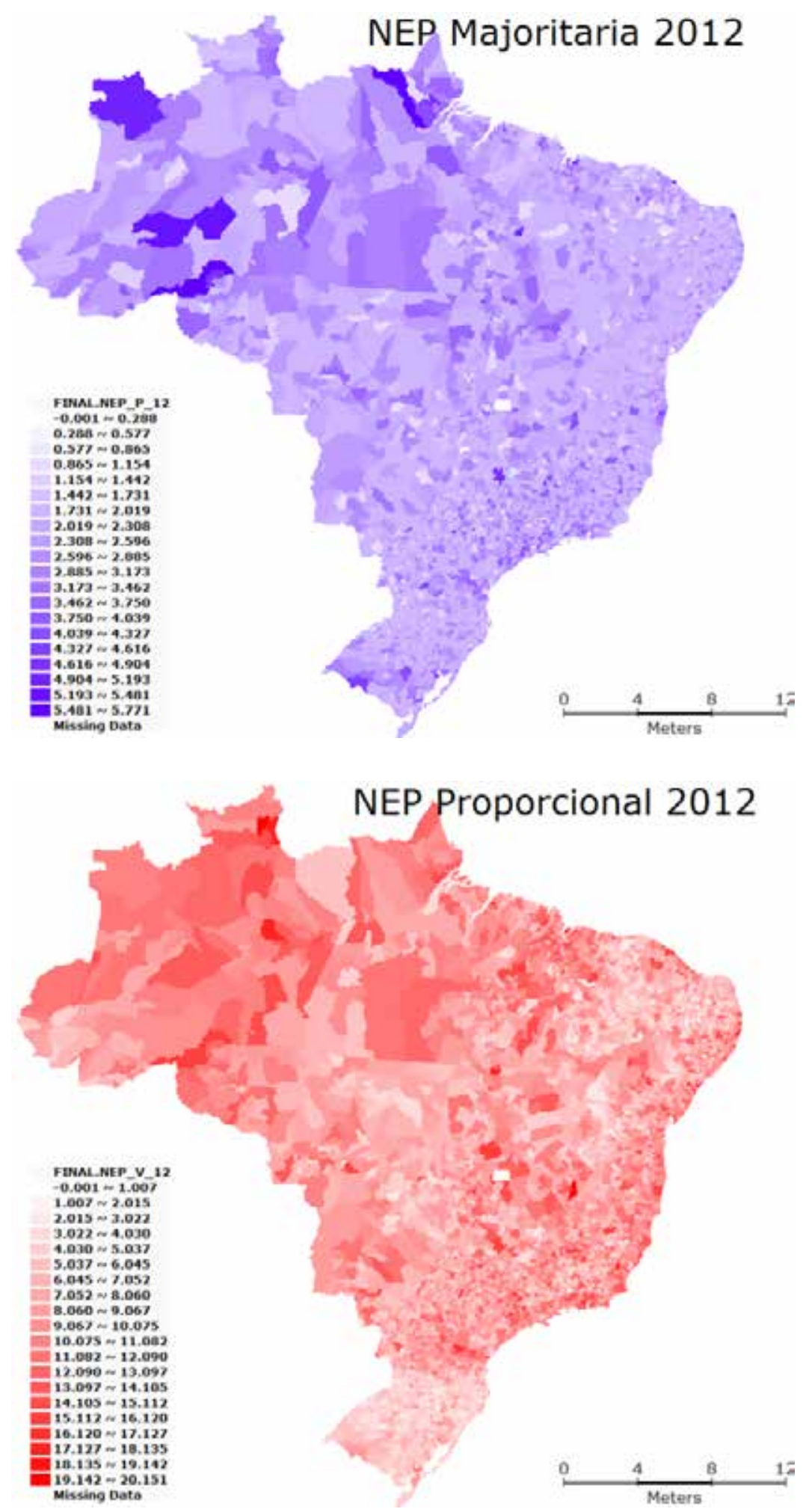


\section{Conclusão}

Este trabalho analisou a evolução da competição política nos municípios nas últimas cinco eleições locais, compreendidas entre 1996 e 2012. Pode-se observar que existem fortes indícios de que foram praticamente eliminados os conhecidos grotões, ainda que haja alguma persistência destes justamente na região menos esperada pelos analistas, ou seja, na região Sul. O número efetivo de partidos para eleições proporcionais tem crescido nos municípios em decorrência não somente de uma fragmentação das forças eleitorais já existentes, mas, sobretudo, pela introdução de novos atores na competição nos sistemas locais. Observou-se um aumento significativo do número de municípios em que os partidos lançam candidatos, com exceção dos grandes partidos nacionais como PMDB, PSDB, DEM/PFL nas eleições majoritárias que já participavam de alguma forma nestas localidades. Nas eleições proporcionais, quase todos os partidos aumentaram o número de municípios que participam lançando candidatos, principalmente os pequenos partidos como PSB, PV, PDT, PSC e PC do B, produzindo um incremento na dispersão das forças eleitorais no nível municipal. Este aumento do número de atores, com especial destaque para o PT e pequenos partidos, e da fragmentação de forças pode ser observado para todas as faixas de tamanho da população.

Em resumo, podemos afirmar que do início da década de 1990 até hoje a política municipal sofreu grandes alterações:

1) Aumentou significativamente o número de competidores nos municípios pela nacionalização do sistema partidário, principalmente, nas eleições proporcionais (eleições para vereadores);

2) O fator institucional (sistema eleitoral majoritário utilizado para eleição de prefeito) é o maior limitador da competição eleitoral. No que concerne ao número de competidores, muito maior do que fatores socioeconômicos dos municípios, esta conclusão baseia-se na comparação entre as variações da competitividade dos sistemas eleitorais - majoritário e proporcional, muito maior neste último em todos os municípios.

4) Diante da pulverização da competição, o domínio dos prefeitos sobre os eleitores vê-se diminuído, dado os riscos de concentrar recursos nas eleições nacionais e perder o apoio do próprio grupo nas eleições seguintes. 
Destarte, ainda que haja diversas formas de se mensurar a competitividade dos sistemas políticos, dos mais simples aos mais complexos indicadores, em todos eles os sistemas políticos locais apresentam maior competitividade hoje do que há 25 anos.

\section{Referências bibliográficas}

AFONSO, J. R. R.; ARAÚJO, É. A. A capacidade de gasto dos municípios brasileiros: arrecadação própria e receita disponível. [s.l.] junho 2001 (mimeo), 2000.

DAHL, R. Poliarquia: participação e oposição. São Paulo: Edusp, 1997. A preface to democratic theory. 2006.

DUVERGER, M. Os partidos políticos. 2. ed. Brasília: Zahar Editores; Universidade de Brasilia, 1980.

LAAKSO, M.; TAAGEPERA, R. Effective number of parties: A measure with application to West Europe. Comparative political studies, v. 12, n. 1, p. 3-27, 1979.

LEAL, V. N. Coronelismo, enxada e voto: o município eo regime representativo no Brasil. [s.I.] Editora Alfa-Omega, 1975. v. 2.

LIMA JR., O. B. Partidos políticos brasileiros. A experiência federal e regional: 1945/1964. 1983.

LIPSET, S. M. Some social requisites of democracy: Economic development and political legitimacy. p. 69-105, 1959. O homem político. [s.I.] Zahar Editores, 1967. p. 440.

NICOLAU, J. Notas sobre os quatro índices mais usados nos estudos eleitorais. In: O sistema partidário brasileiro, Rio de Janeiro, FGV (1998). Rio de Janeiro: FGV Editora, 1997. Multipartidarismo e democracia: um estudo sobre o sistema partidário brasileiro, 1985-1994. Rio de Janeiro: Fundação Getulio Vargas Editora, 1996.

SARTORI, G. Engenharia constitucional: como mudam as constituições. Brasília: [s.n.].

Recebido: 2/10/2014

Aceito: 5/12/2014 